\title{
Digital simulation research of construction risk at the entrance of Shanchongjing tunnel
}

\author{
Mingqi Liu ${ }^{1}$, QiongfenWang ${ }^{1 *}$ \\ ${ }^{1}$ College of Civil Engineering, Southwest Forestry University, Kunming 650224, P.R. China.
}

\begin{abstract}
The tunnel section of the highway tunnel is an important part of tunnel construction. Once accidents such as instability of the side slope and collapse of the palm face occur, it will affect the construction progress at a slight level, and will result in unpredictable economic losses and even casualties. Therefore, in the construction of highway tunnels, the opening section has always been taken as the key point of tunnel construction. Carrying out safety risk assessment on the construction stage of the tunnel section can discover the risks in time, so as to propose reasonable and feasible countermeasures to reduce the risks and reduce the consequences of the risks.
\end{abstract}

\section{Introduction}

This simulation is based on the original construction plan using a three-stage construction method for modeling using the MIDAS / GTS finite element software to divide the reservoir into hex meshes. In accordance with the Saint-Venant principle, when stress is redistributed, the stress distribution changes significantly at a location very close to the load. Locations farther from the load have minimal impact, and locations with minimal impact are usually distributed 3-5 diameters from its center of the tunnel. Consequently, the volume of this model is determined as follows: the width of the reservoir model is $100 \mathrm{~m}$, the longitudinal length is $30 \mathrm{~m}$, the tunnel span is $16 \mathrm{~m}$, the lower part of the tunnel is $40 \mathrm{~m}$. The reservoir consists of red alluvial soil, completely weathered sandstone, and sandstone layers with moderate weathering from top to bottom. The size of the one-off cut is $3 \mathrm{~m}$, the bed mesh is divided into $3 \mathrm{~m}$, and the tunnel mesh is divided into $1 \sim 1.5 \mathrm{~m}[1,2]$.

Figure 1 shows the mesh separation of the three-stage methodical model of the entrance to the Shanchongjing Tunnel. Figure 2 shows the supporting structure of the three-stage method, and Figure 3 shows the three-stage excavation model.

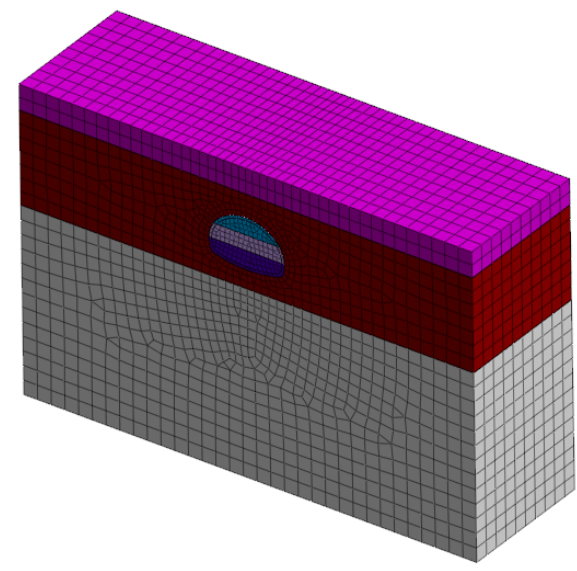

Fig.1 Three-step method to simulate meshing

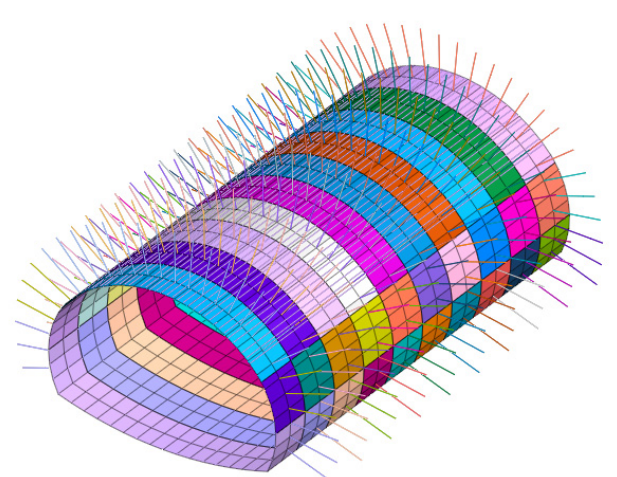

Fig.2 Supporting structure diagram 


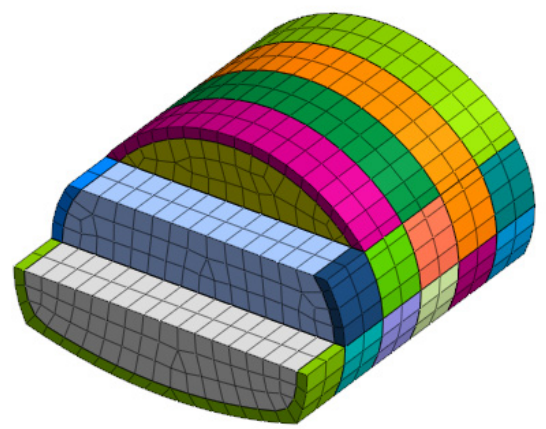

Fig.3 Three-step excavation model

\section{Analysis of digital simulation results}

In accordance with the original construction plan, a three-stage method was chosen to excavate the entrance of the Shanchongjing tunnel. Using MIDAS / GTS to digitally simulate the diagram, once the calculation is complete, the displacement and stress cloud diagrams can be generated for each stage of the construction of the three-stage calculation modele[3].

(1) Vertical displacement of enclosing rock

Vertical displacement ( $\mathrm{Z}$ direction) of the enclosing rock after excavation of the first stage and the entire excavation of the portal section of the Shanchongjing tunnel, perpendicular to the plane of the tunnel. Details are shown in fig. 4-5.

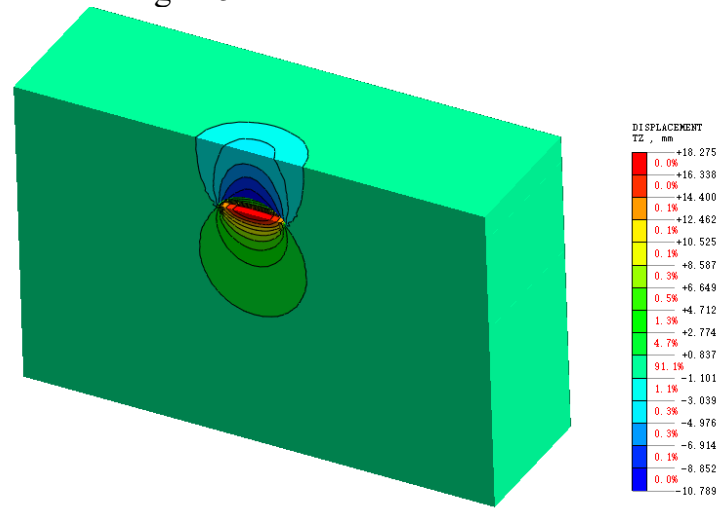

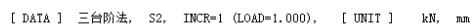

Fig.4 Vertical displacement diagram after the first step of the three-step method is completed $(\mathrm{mm})$
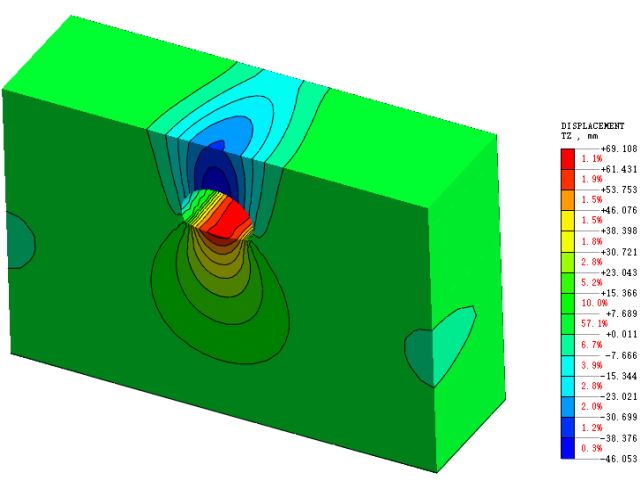

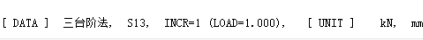

Fig.5 Vertical displacement after the completion of all excavations with the three-step method $(\mathrm{mm})$
It can be seen that the deformation of the enclosing rock gradually increases as the initial stress is removed and subsequent construction steps are taken to excavate the portal section of the tunnel using the three-stage method. After completing the first step of the three-stand method, the maximum vertical displacement (along the $\mathrm{Z}$-axis) occurs directly above the tunnel roof, the value is $10.79 \mathrm{~mm}$, and the maximum deformation of the arch bottom is $18.28 \mathrm{~mm}$. After the completion of the digging of the tunnel, the maximum settlement value also occurs just above the tunnel roof, which is $46.05 \mathrm{~mm}$, and the maximum deformation of the rise of the arch bottom is $69.11 \mathrm{~mm}$.

(2) Horizontal displacement of enclosing rock

The horizontal displacement ( $\mathrm{X}$ direction) of the enclosing rock after the first stage of excavation and the entire excavation of the Shanchongjing tunnel portal is vertical with respect to the tunnel axis. Details are shown in fig. 6-7.

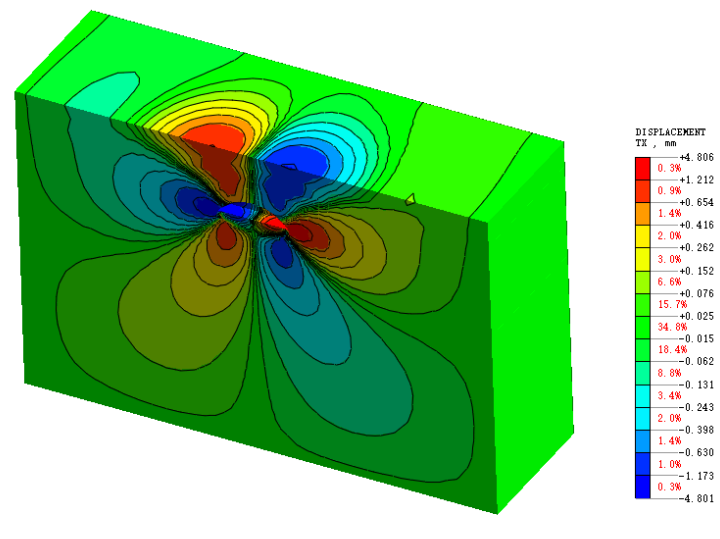

Fig.6 Horizontal displacement after the first step of the three-step method is completed ( $\mathrm{mm})$

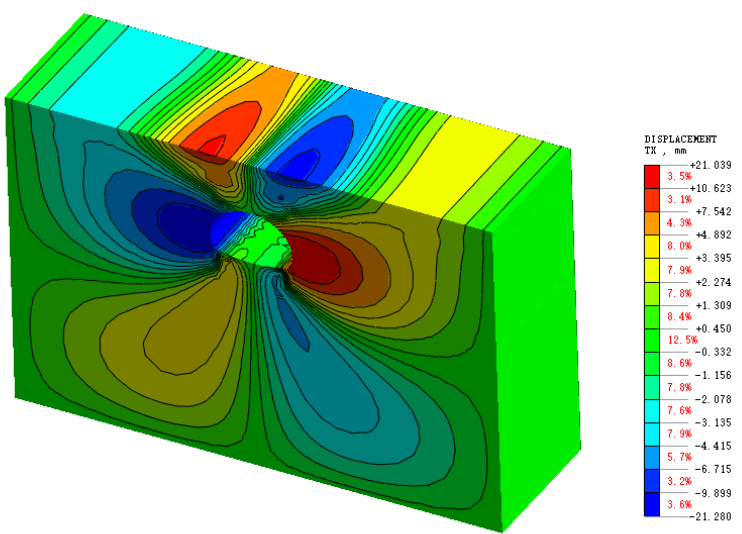

[ DATA ] 三台岎法, S13, INCR=1 (LOAD $=1,000), \quad$ [ UNIT ] $\mathrm{kN}, \mathrm{mm}$

Fig.7 Horizontal displacement after the completion of all excavations with the three-step method ( $\mathrm{mm}$ )

It can be seen that when excavating the portal section of a tunnel with the three-shoulder method, the maximum horizontal displacement (x-direction) is 4.81 $\mathrm{mm}$ after the first stage of excavation using the three-shoulder method, which occurs on both sides of the upper bench. After excavation, the maximum displacement in the horizontal direction (x direction) is 
$21.28 \mathrm{~mm}$, which occurs at the arch chord and arch foot.

(3) Stress analysis of enclosing rock

The tunnel has certain disturbances in the enclosing rock during excavation and tunnel construction. After the initial support is completed, the stress of the enclosing rock will be redistributed to achieve a new equilibrium state. The stress characteristics and distribution law of the enclosing rock can be understood through digital simulations using finite element software, which can provide the necessary basis for tunneling engineers to determine the stability of the enclosing rock. The portal section of the Shanchongjing tunnel is excavated by the three-girder method. The maximum main stress diagram is shown in Figure 8 and the minimum main stress diagram is shown in Figure 9.

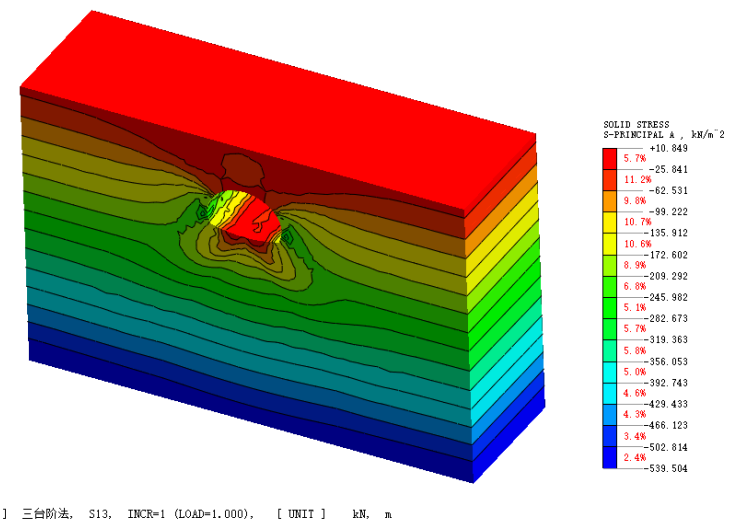

Fig.8 Three-step method maximum principal stress diagram $(\mathrm{KPa})$

Tab.1 Allowable relative displacement values around the tunnel (\%)

\begin{tabular}{cccc}
\hline \multirow{2}{*}{ Type of enclosing rock } & \multicolumn{3}{c}{ Overburden cover $/ \mathbf{m}$} \\
\cline { 2 - 4 } & $<\mathbf{5 0}$ & $\mathbf{5 0} \sim \mathbf{3 0 0}$ & $>\mathbf{3 0 0}$ \\
\hline III & $0.10 \sim 0.30$ & $0.20 \sim 0.50$ & $0.40 \sim 1.20$ \\
IV & $0.15 \sim 0.50$ & $0.40 \sim 0.12$ & $0.80 \sim 2.00$ \\
V & $0.20 \sim 0.80$ & $0.60 \sim 1.60$ & $1.00 \sim 3.00$ \\
\hline
\end{tabular}

When monitoring the surrounding tunnel displacement, the distance between the two peripheral convergence measurement points is about $17 \mathrm{~m}$. Therefore, according to the peripheral relative displacement early warning value, the permissible convergence displacement value around the tunnel and the permissible vault settlement displacement are shown in Table 2[5].

Tab. 2 Peripheral maximum displacement value (mm)

\begin{tabular}{cccc}
\hline \multirow{2}{*}{$\begin{array}{c}\text { Type of enclosing } \\
\text { rock }\end{array}$} & \multicolumn{3}{c}{ Overburden cover/m } \\
\cline { 2 - 4 } & $<\mathbf{5 0}$ & $\mathbf{5 0} \sim \mathbf{3 0 0}$ & $>\mathbf{3 0 0}$ \\
\hline III & 25 & 40 & 100 \\
IV & 40 & 100 & 160 \\
V & 60 & 120 & 240 \\
\hline
\end{tabular}

The actual measurement and the maximum allowable displacement are written as $u$ and $U_{n}$ respectively. Based on the dynamic construction monitoring scheme, the portal section of the tunnel is effectively controlled and the construction is managed and guided according to the following safety criteria, as shown in Table 3.

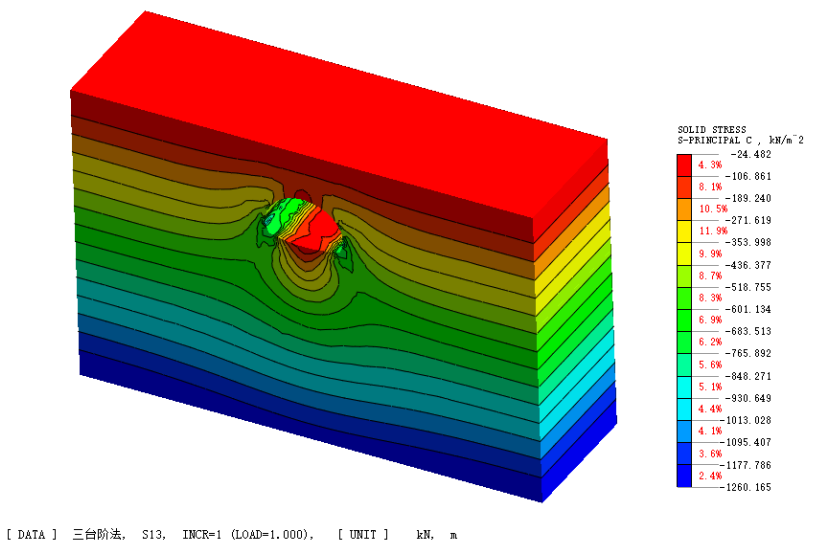

Fig.9 Three-step method minimum principal stress diagram $(\mathrm{KPa})$

It can be seen from this that the stress concentration of the tunnel portal after excavation mainly occurs in the arch, belt and bottom of the arch, the effective tensile stress is $10.85 \mathrm{kPa}$ in the arch and bottom of the arch, and the effective compressive stress is at the level of the hance arch and the arch of the foot. and the above stress values are within the allowable stress range.

It can be seen from this that the stress concentration of the tunnel portal after excavation mainly occurs in the arch, belt and bottom of the arch, the effective tensile stress is $10.85 \mathrm{kPa}$ in the arch and bottom of the arch. The effective compressive stress is at the level of the hance and the arch of the foot. For effective compressive stress, the above stress values are all within the allowable stress rangee[4].

Tab. 3 Displacement management level

\begin{tabular}{ccc}
\hline $\begin{array}{c}\text { Managerial } \\
\text { class }\end{array}$ & $\begin{array}{c}\text { Management } \\
\text { displacement }\end{array}$ & Construction status \\
\hline III & $\begin{array}{c}\mathrm{U}<\left(\mathrm{U}_{\mathrm{n}} / 3\right) \\
\left(\mathrm{U}_{\mathrm{n}} / 3\right) \leq \mathrm{U} \leq \\
\left(2 \mathrm{U}_{\mathrm{n}} / 3\right)\end{array}$ & $\begin{array}{c}\text { Normal construction } \\
\text { Reinforced mount } \\
\text { required }\end{array}$ \\
II & $\begin{array}{c}\text { Excavation works must } \\
\text { be stopped immediately } \\
\text { and special measures } \\
\text { must be taken }\end{array}$ \\
\hline I & $\mathrm{U}>\left(2 \mathrm{U}_{\mathrm{n}} / 3\right)$ & \\
\hline
\end{tabular}

\section{Conclusions}

The portal section of the tunnel is designed with a depth of $10.5 \mathrm{~m}$, which is less than $50 \mathrm{~m}$, and its enclosing rock has a degree of $\mathrm{v}$. According to table 3 of the tunnel, it can be seen that the maximum allowable displacement of the surrounding convergence of the draft of the tunnel roof is $60 \mathrm{~mm}$. Based on the analysis of the digital simulation results, it can be seen that during the 
excavation process, the horizontal displacement has a maximum value in the hance of the arch, which is 21.28 $\mathrm{mm}$, and the result is between $\mathrm{U}_{\mathrm{n}} / 3 \sim 2 \mathrm{U}_{\mathrm{n}} / 3$, which refers to the level of level movement control II, and support needs to be strengthened; the maximum vertical subsidence of the enclosing rock occurs at the top of the arch of $46.05 \mathrm{~mm}$, and the result exceeds $2 \mathrm{U}_{\mathrm{n}} / 3$, which is related to the level of displacement control of the $1 \mathrm{st}$ degree. Therefore, earthworks should be stopped immediately and special measures should be taken. To summarize, it can be seen that the portal section of the tunnel faces serious potential safety hazards during the construction process, so earthworks should be stopped immediately and a number of tunnel strengthening measures should be taken to provide a reliable guarantee for the safety of tunnel construction.

\section{References}

1. M.H.Faber.M.G. Stewart.Risk Assessment for Civil Engineering Facilities: critical Overview and Discussion[J]. Reliability Engineering and System Safety, 2003, 80: 173-184.

2. Einstein H.H., Chiaverio P., and Kappel U. Risk Analysis for the Under Tunnel[J]. Tunnels \& Tunnelling. 1994, 26(11): 28-30.

3. Einstein H.H. The Decision Aids for Tunnelling an Update[J]. Transportation Research Record. 2004.

4. Aliahmadi A., Sadjadi S. J, Jafar- Eskandari M. Design a New Intelligence Expert Decision Making Using Game Theory and Fuzzy AHP to Risk Management in Design Construction and Operation of Tunnel Projects(Case Studies: Result Tunnel[J]. International Journal of Advanced Manufacturing Technology, 2010: 1-10.

5. Likhitruangsilp, Veerasak. Analysis of Risk Response Measures for Tunneling Projects[J]. Construction Research Congress 2012: Construction Challenges in a Flat Word Proceedings of the 2012 Construction Research Congress, 2012(5): 258-267. 